\title{
Clinical Study \\ Sex Differences in the Effects of Inhaled Corticosteroids on Weight Gain among Patients with Asthma
}

\author{
Amanda K. Rizk, 1, 2, 3,4 Kim L. Lavoie, , 4,5 Véronique Pepin, 1,3,4 \\ Alicia Wright, ${ }^{3,4}$ and Simon L. Bacon ${ }^{1,3,4,6}$ \\ ${ }^{1}$ Centre de Recherche, Hôpital du Sacré-Cour de Montréal-A University of Montreal Affiliated Hospital, \\ 5400 Boulevard Gouin West, Montreal, QC, Canada H4J 1C5 \\ ${ }^{2}$ Special Individualized Program, Concordia University, 7141 Sherbrooke Street West, Montreal, QC, Canada H4B 1R6 \\ ${ }^{3}$ Department of Exercise Science, Concordia University, 7141 Sherbrooke Street West, Montreal, QC, Canada H4B 1R6 \\ ${ }^{4}$ Montreal Behavioural Medicine Centre, Montreal, QC, Canada \\ ${ }^{5}$ Département de Psychologie, Université du Québec à Montréal (UQAM), P.O. Box 8888, Succursale Centre-Ville, \\ Montreal, QC, Canada H3C 3P8 \\ ${ }^{6}$ Research Centre, Montreal Heart Institute-A University of Montreal Affiliated Hospital, \\ 3600 Rue Bélanger, Montreal, QC, Canada H1T 1 C8
}

Correspondence should be addressed to Simon L. Bacon, simon.bacon@concordia.ca

Received 1 August 2012; Accepted 16 August 2012

Academic Editors: A. M. Boylan, A. P. Comellas, A. Kurdowska, K. Nishimura, and C. C. Witt

Copyright ( $) 2012$ Amanda K. Rizk et al. This is an open access article distributed under the Creative Commons Attribution License, which permits unrestricted use, distribution, and reproduction in any medium, provided the original work is properly cited.

\begin{abstract}
Background. Studies have shown that asthma and asthma exacerbations are related to body weight and that this relationship might be sex-specific. While oral corticosteroids have been associated with weight gain, little is known about the effect of inhaled corticosteroid (ICS) use on short-term weight gain. The purpose of the present study was to examine whether ICSs would be associated with weight gain among asthmatic patients. Methods. A total of 180 adult patients with physician-diagnosed asthma provided details of their medical history and demographic information, along with height and weight at baseline and at one year. Weight change was defined as follow-up minus baseline weight. General linear models were used to assess the relationship between ICS dose (fluticasone propionate equivalent) and sex. Results. Significant main effects of sex $(P=.005)$ and ICS dose $(P=.036)$ and an interaction effect of sex and ICS dose $(P=.003)$ on weight change were observed. Further analysis of the interaction indicated that women had greater weight gain, while men had decreased weight with increased ICS dose. Conclusions. Findings suggest that ICSs may trigger weight gain in females and highlight the need for studies to confirm this relationship and examine the potential underlying mechanisms.
\end{abstract}

\section{Introduction}

One of the main physiological characteristics associated with asthma is chronic airway inflammation, which is usually controlled through the use of inhaled corticosteroids (ICSs) [1]. This medication is commonly prescribed as a preventative treatment to reduce and manage the number of exacerbations experienced by asthmatic patients [1]. With its introduction in 1972, it was created with the intention of minimizing adverse effects normally associated with oral corticosteroids, including decreased bone mineral density, cataracts, ecchymosis, skin atrophy, ocular hypertension, glaucoma, and weight gain, by creating a direct pathway to the lungs thereby decreasing systemic absorption [2]. Despite these intentions, research has revealed that ICS's bring about some adverse systemic effects while still remaining more systemically efficient and safe compared to their oral counter-parts $[1,3-5]$. One adverse effect of oral corticosteroids, which has not been widely assessed with ICS's in adults, is weight gain.

Worldwide, the prevalence of obesity has more than doubled since 1980 [6]. In 2008, 1.5 billion adults, 20 years of age and older, were overweight. Of these overweight 
individuals, over 200 million men and nearly 300 million women were considered obese [6]. These increases have a profound impact on the prevalence of a wide variety of chronic diseases [7], including asthma. Numerous studies have revealed an association between asthma and obesity [812], though the mechanistic link between the two $[13,14]$ and their temporal association remain hotly debated. As such, it is important to examine whether ICS's could possibly be associated with weight gain in an asthmatic population. In the present study, it was hypothesized that the use of ICS's would result in short-term (one-year) weight gain among patients with asthma. A secondary goal was to investigate the sex-specific nature of this relationship, as it has been suggested that the link between asthma and obesity may be more prevalent among women [11]. As such, it was hypothesized that women with asthma would have a greater weight gain at one year compared to men.

\section{Methods}

2.1. Study Participants. Patients in this prospective study were recruited from the asthma outpatient clinic at l'Hôpital du Sacré-Coeur de Montréal from June 2003 to Dec 2006. A total of 801 patients were recruited at baseline, constituting $94 \%$ of all eligible patients. Of those patients, $180(22.5 \%)$ returned at one year for a clinically required followup and were reassessed as part of the present substudy. Patients were eligible to participate if they had physician-diagnosed asthma (confirmed by spirometry and/or methacholine challenge), were between the ages of 18 and 75 years, and were fluent in English or French. Patients were ineligible to participate if they had a comorbid disease which conferred greater risk for morbidity than asthma (i.e., COPD, cardiovascular disease, etc.), a primary diagnosis of occupational asthma, the presence of severe psychopathology (e.g., schizophrenia), dementia, substance abuse, or if they were pregnant. More specifically, patients were confirmed as having asthma by chart-documented bronchodilator reversibility in $\mathrm{FEV}_{1} \geq$ $20 \%$ predicted and/or a $20 \%$ fall in $\mathrm{FEV}_{1}$ after metacholine challenge [15]. One person was excluded from the analyses as they had a baseline body mass index (BMI) greater than $50 \mathrm{~kg} / \mathrm{m}^{2}$. This study was approved by the institutional ethics research board and all participants provided written, informed consent prior to participating in this study.

2.2. Study Design. This study was conducted as part of a larger epidemiological study assessing psychosocial risk factors for asthma morbidity (Psychosocial and Behavioural Risk Factors for Asthma Longitudinal Study, PAL Study) [16]. During the baseline visit, patients underwent a sociodemographic and medical/asthma history interview, during which patient's self-reported height and weight and all medications were recorded. For patients taking ICS medication, information regarding type of medication and dosage were obtained. All clinical information and medications were systematically verified through chart review. All participants provided the same information at the one-year follow-up visit.
2.3. Measures. Self-reported height and weight values were obtained from the patients to calculate BMI (weight in $\mathrm{kg} /$ height in $\mathrm{m}^{2}$ ). Weight status was classified as normal for patients with a BMI less than $25 \mathrm{~kg} / \mathrm{m}^{2}$, overweight for patients with a BMI between $25 \mathrm{~kg} / \mathrm{m}^{2}$ and $29.9 \mathrm{~kg} / \mathrm{m}^{2}$, or obese for those with a BMI equal to or exceeding $30 \mathrm{~kg} / \mathrm{m}^{2}$. With respect to ICS use, participants provided details about the frequency and dose of ICS medication. All values were converted to fluticasone propionate equivalents and reported as dose per day. All patients underwent standard pulmonary function testing using standard spirometry in the respiratory laboratory by a trained respiratory technician on the day of the patient's visit. Rescue medication was withheld for at least 4 hours (but up to 8) prior to testing. Predicted values of $\mathrm{FEV}_{1}$ and $\mathrm{FVC}$ were calculated from reference values for patients less than [17] and greater than [18] 70 years of age, respectively, yielding percentage of the predicted $\mathrm{FEV}_{1}$ and percentage of the predicted $\mathrm{FEV}_{1} / \mathrm{FVC}$ ratio.

\subsection{Data Reduction and Analyses}

2.4.1. Main Analyses. Weight change was defined as followup weight minus baseline weight. General linear models (GLMs) were used to assess the relationship between ICS dose and sex, defined as our independent variables, and weight change, defined as our dependent variable. Covariates were defined a priori based on their potential influence on the expected relationships under investigation and included age, baseline smoking status, change in smoking status, level of education, baseline weight, duration of asthma, use of oral corticosteroids, and baseline $\mathrm{FEV}_{1}$. All patients with data at 1 year were included in the analyses. All statistical analyses were performed using SAS v9.1 (SAS, Cary) and $P<.05$ was considered statistically significant.

2.4.2. Missing Data. Our missing data analysis procedures used missing at random (MAR) assumptions, as per Rubin's rules [19]. We used the PROC MI method of multiple multivariate imputation in SAS. We independently analyzed 5 copies of the data, each with missing values suitably imputed, in the GLM analyses. Using PROC MIANALYZE, we averaged estimates of the variables to give a single mean estimate and adjusted standard errors according to Harrell's guidelines [20]. Details of the amount of missing data per variables are included in Table 1.

\section{Results}

Baseline sociodemographic, clinical, and asthma characteristics are presented in Table 1. A total of $61 \%$ of the participants were women and had a mean (SD) age of 51 (14). The mean \pm SD of ICS dose (fluticasone propionate equivalent) was $776 \pm 568 \mu \mathrm{g}$ for women and $716 \pm 460 \mu \mathrm{g}$ for men. Clinical/asthma characteristics are indicative of an asthmatic population from a tertiary care setting; as such, it is unsurprising that ICS doses were generally higher than those found in asthmatic populations followed in primary care [21]. 
Table 1: Patient demographics.

\begin{tabular}{|c|c|c|c|}
\hline Characteristics & Women & Men & Percentage of missing information $(n)$ \\
\hline \multicolumn{4}{|l|}{ Sociodemographics } \\
\hline$n^{\#}$ & 109 & 71 & $0(0)$ \\
\hline Age, $\mathrm{yr}^{\#}$ & $51.4 \pm 13.5$ & $48.3 \pm 13.5$ & $2(4)$ \\
\hline White race, \% (n) & $94(100)$ & $91(64)$ & $2(4)$ \\
\hline Education, $\mathrm{yr}^{\#}$ & $12.9 \pm 3.4$ & $13.4 \pm 3.7$ & $4(7)$ \\
\hline Employed, \% ( $n)$ & $64(66)$ & $73(51)$ & $4(7)$ \\
\hline Cohabitating, \% $(n)$ & $65(67)$ & $70(49)$ & $4(7)$ \\
\hline Weight, $\mathrm{kg}^{\#}$ & $67.5 \pm 15$ & $87.2 \pm 19.3$ & $2(4)$ \\
\hline Baseline BMI, kg/m² & $26 \pm 5.4$ & $28.1 \pm 6.3$ & $2(4)$ \\
\hline \multicolumn{4}{|l|}{ Pulmonary function } \\
\hline $\mathrm{FEV}_{1}, \%$ predicted $^{\#}$ & $78.0 \pm 19.5$ & $76.2 \pm 21.5$ & $7(13)$ \\
\hline FVC, $\%$ predicted $^{\#}$ & $88.0 \pm 16.3$ & $89.0 \pm 20.2$ & $8(14)$ \\
\hline $\mathrm{FEV}_{1} / \mathrm{FVC}, \%$ predicted & $72.6 \pm 10.7$ & $69.3 \pm 10.1$ & $8(14)$ \\
\hline \multicolumn{4}{|l|}{ Asthma history } \\
\hline Asthma control (ACQ level) & $1.5 \pm 1.1$ & $1.4 \pm 0.9$ & $2(4)$ \\
\hline Atopic $\#$, \% (n) & $69(72)$ & $70(49)$ & $3(5)$ \\
\hline \multicolumn{4}{|l|}{ Asthma medications } \\
\hline Short-acting $\beta_{2}$-agonists ${ }^{\#}, \%(n)$ & $96(102)$ & $100(70)$ & $2(4)$ \\
\hline Long-acting $\beta_{2}$-agonists ${ }^{\#}, \%(n)$ & $83(88)$ & $74(52)$ & $2(4)$ \\
\hline $\mathrm{ICS}^{\#}, \%(n)$ & $100(106)$ & $99(69)$ & $2(4)$ \\
\hline ICS $\operatorname{dose}^{* \#}, \mu \mathrm{g}$ & $776 \pm 568$ & $716 \pm 460$ & $14(25)$ \\
\hline Oral corticosteroids ${ }^{\#}, \%(n)$ & $13(14)$ & $6(4)$ & $2(4)$ \\
\hline Antileukotrienes $^{\#}, \%(n)$ & $15(16)$ & $10(7)$ & $2(4)$ \\
\hline Antirhinitics,$\%(n)$ & $25(27)$ & $14(10)$ & $2(4)$ \\
\hline
\end{tabular}

Data are presented as mean \pm SD or $\%$ (no.).

FEV: forced expiratory volume; FVC: forced vital capacity; ICS: inhaled corticosteroids.

* Fluticasone propionate equivalent $(\mu \mathrm{g})$.

\# Used in the multiple imputation process.

The analyses revealed a significant main effect of sex $(\beta$ $(95 \% \mathrm{CI})=4.099(1.221-6.976), P=.005)$ and ICS dose $(\beta(95 \% \mathrm{CI})=.002(.0001-.004), P=.036)$, as well as a significant interaction effect of sex and ICS dose $(\beta(95 \%$ $\mathrm{CI})=-.005(-.008--.002), P=.003)$ on weight change. The interaction effect indicated that for women, increasing ICS dose was associated with greater 1-year weight, while for men, higher ICS dose at baseline predicted lower weight change at 1 year (Figure 1). Based on separate regression models for women and men, it would appear that for every $500 \mu \mathrm{g}$ of fluticasone equivalent of ICS at baseline, men would lose $1.30 \mathrm{~kg}$ (95\% CI $=-2.84-0.25)$ of weight at 1 year, whereas women would gain $0.94 \mathrm{~kg}(95 \% \mathrm{CI}=0-1.89)$ of weight. For the combined cohort of women and men, a gain of $1.07 \mathrm{~kg}(95 \% \mathrm{CI}=.07-2.07)$ was observed.

To assess the potential causal pathways of this relationship, an analysis of the impact of baseline body weight on 1 year ICS dose was conducted. This analysis revealed no significant main effect of sex $(\beta(95 \% \mathrm{CI})=409.65(-864.21-$ $869.15), P=.995)$, weight $(\beta(95 \% \mathrm{CI})=3.88(-12.86-$ $3.62), P=.252)$, nor their interaction $(\beta(95 \% \mathrm{CI})=5.21$ $(-10.81-11.27), P=.965)$ on ICS dose change. For all analyses, the same pattern of results was seen if baseline BMI was used instead of weight.

\section{Discussion}

Findings from the current study showed that women taking higher dosages of ICS's experienced greater increases in weight over the course of one year, with an average gain of.94 kg (2.1 lbs) per year, while men tended to experience a decrease in weight with an increase in ICS dose, with an average loss of $1.3 \mathrm{~kg}$ (2.9 lbs) per year. Similar results were obtained in a previous study conducted in asthmatic children. Indeed, Jani et al. [22] found that asthmatic children aged one to twelve years receiving ICS doses above $400 \mu \mathrm{g} /$ day had an annual increase of $.44 \mathrm{~kg} / \mathrm{m}^{2} /$ year $(P=.0003)$ in BMI compared with those receiving less than $200 \mu \mathrm{g} /$ day, who showed an increase of $.10 \mathrm{~kg} / \mathrm{m}^{2} /$ year $(P=.0003)$. These results were independent of the type of ICS and inhaler device utilized [22]. This study did not, however, explore sex differences [22]. To our knowledge, no other study has investigated the association between ICS dose and weight gain in an adult population. One study conducted by Hedberg and Rössner did, however, investigate if a relationship exists between body weight and asthma medications in a Swedish population 16-60 years of age $(n=$ 17,912 ). They found there to be no strong evidence to suggest such a relationship in men or women [23]. 


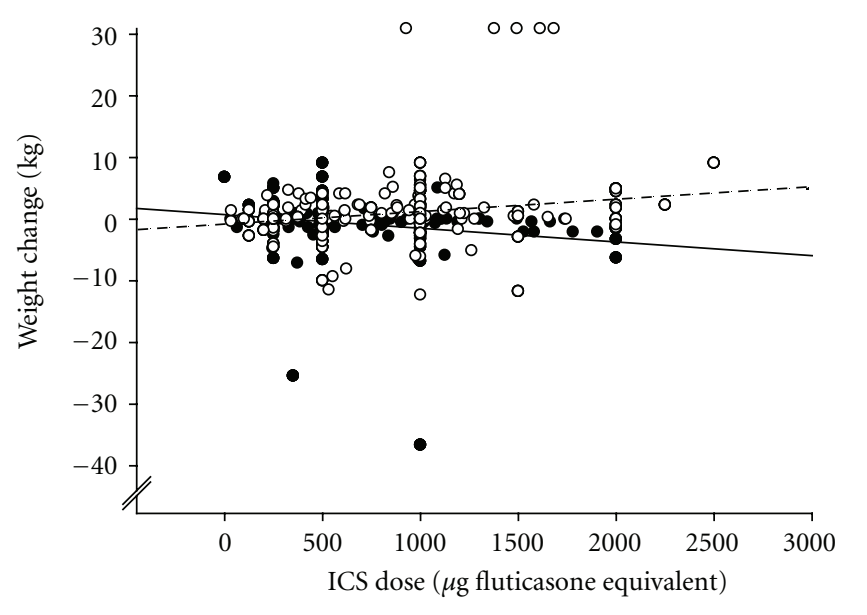

- Men

- Women

FIGURE 1: Relationship between change in weight $(\mathrm{kg})$ and ICS dose ( $\mu \mathrm{g}$ fluticasone equivalent) in women (dashed line) and men (solid line).

Several researchers have explored the obesity-asthma phenomenon and identified this relationship as a sex-specific one, where women with increased BMI's are at greater risk for asthma than women with lower BMIs [9, 12, 24, 25]. For example, a study conducted by Beckett et al. concluded that weight gain disposes young females to new asthma diagnoses, independent of physical activity [24]. However, this relationship was not observed in young males. In a larger study, Chen and colleagues [25] investigated the relationship between asthma and energy expenditure and concluded that obesity was related to the development of asthma in women but not in men. Once again, physical inactivity measured by energy expenditure did not explain this association [25].

An extensive body of literature suggests a strong correlation between obesity and asthma [9-11, 24, 26]. Though controversial, the current paradigm of directionality for this relationship is that obesity increases the risk of developing asthma $[9-11,24,25]$. There are a number of potential mechanisms that may help explain this directional association [27]. These mechanisms include genetics [28], obesity leading to histological changes within the lung [29], decreased airway caliber as a result of chest restriction [30], and sex hormones being influenced by obesity subsequently increasing the risk of asthma [31, 32]. However, it has also been indirectly proposed that asthma may lead to obesity. For instance, oral corticosteroids have been shown to bring about weight gain through systemic absorption of this medication, thereby suppressing the hypothalamicpituitary-adrenal (HPA) axis, which in turn brings about weight gain [33]. It is possible that such a pathway may explain the current findings. It has been suggested that when an ICS is taken, $10-40 \%$ of the medication reaches the lung and $60-90 \%$ is swallowed [34]. This swallowed portion gets absorbed by the gastrointestinal tract and then passes through the liver leaving a fraction bioavailable to reach the systemic circulation [34]. Once in the systemic circulation, unwanted adverse effects may be experienced; furthermore, it has been reported that these effects are dose-dependent $[34,35]$. Though we were not able to assess this in the current study, it represents an important avenue for future research and highlights the importance of using appropriate inhaler techniques among asthmatics.

Given the differential weight gain in women compared to men in the current study, it is possible that female hormones may play a role in this relationship. The most compelling evidence that female sex hormones play a role in asthma appears in natural models (i.e., menstrual cycle, pregnancy, and menopause) [14]. Sex differences can actually be observed as early as gestation, where the lung of a female fetus matures more rapidly than that of a male fetus [36]. During childhood, the prevalence of asthma is higher in boys than in girls; a relationship that is reversed once girls reach puberty, a stage when estrogen levels are higher suggesting a possibly etiological role $[13,37]$. In addition, asthma symptoms have been shown to subjectively worsen during menstruation [38, 39], although other studies have contradicted this finding [40]. In addition, pregnancy is generally characterized by changes in asthma symptoms, ranging from improvements (i.e., reductions in airway hyperresponsiveness) to a worsening of asthma symptoms [13]. A study conducted by Troisi et al. [41] evaluated the association between hormone replacement therapy (conjugated estrogens) and increased asthma incidence. These investigators found that women who were naturally menopausal and reported never using postmenopausal hormones had a significantly lower risk of incident asthma compared to premenopausal women [41]. Finally, estrogens could act in synergy with leptin, which plays a central role in fat metabolism through the regulation of energy intake and expenditure and is positively correlated with body fat and BMI [42]. Leptin receptors exist in human lung tissue [43] and plasma leptin levels have been observed to be higher in women compared to men, independent of obesity [44]. Cytokines, such as IL-6, IL- $1 \beta$, and TNF- $\alpha$, are also involved in metabolism and food intake. TNF- $\alpha$ and IL-1 $\beta$ both modulate the release of leptin, and TNF$\alpha$ and IL- 6 act directly on the hypothalamus by altering the regulation of food intake $[45,46]$. These relationships suggest that estrogen (both alone and via interactions with leptin) may play a key role in the pathophysiology of asthma and could perhaps help explain why sex differences were observed in this study. Aside from sex hormones, the fact that men tend to have more muscle mass than fat mass as compared to women may have also contributed to the sex differences observed in this study. In addition, the weight loss experienced by men could have improved asthma control thereby reducing the need for medication use [47].

Several behavioural factors may also help explain sex differences in the relationship between ICS use and weight gain. A study conducted by Sundberg and colleagues [48] comparing sex differences among 470 asthmatic men and women found that women had greater self-reported adherence to ICS's and tended to have a more positive attitude towards their medication, relative to men. Furthermore, women reported having a higher prevalence of insomnia and day-time sleepiness compared to men, which has been 
proposed by some as a potential cause of weight gain [48]. Future studies are needed to clarify sex differences in behavioural factors associated with weight gain and ICS use among asthmatic patients.

4.1. Study Limitations and Strengths. The results of this study need to be interpreted in the context of some limitations. The current study utilized self-report measures of height and weight to calculate BMI. However, data from the National Health and Nutrition Examination Survey (NHANES-III) study suggests that the BMI values derived from self-reported height and weight are highly correlated $(r=.89$ to .97 , $P<.001)$ with measured height and weight values in both men and women [49], particularly in individuals under the age of 60 , which is well within the average age (i.e., 50 years) of the present sample. A second limitation is that this was a convenience sample, as we only have data on a subset of patients who returned to the clinic for the oneyear followup. As a result, our sample population may be somewhat biased in the sense that those who returned would be expected to have the most severe or poorly controlled asthma (as shown in Table 1 in their relatively higher ACQ scores). An example of this is the fact that there was a higher than usual number of people with a prescription of oral corticosteroid (though this was still a relatively low proportion, ca. 10\%) and the use of such medications may have had an impact on our main question. To account for this we did adjust for oral corticosteroid use in our analyses. Though this population may not be consistent with a family physician seen population of asthmatics, it may be the most relevant group to examine due to their poor control thereby requiring higher ICS doses, thus making them at potentially higher risk for weight gain. In addition, ICS adherence was not measured in this study, which may have influenced the overall weight changes observed in the present study, and the relative weight gain observed in men versus women if adherence differed by sex. In general, asthma patients tend to show poor adherence to ICS's [50-52]. Given that we found that increased prescribed doses of ICS's were associated with increased weight gain in women, if patients were less adherent to their medications, this would suggest that our results would, at worst, reflect an underestimation of the effects of ICS on body mass. In addition, a study by Ip et al. [4] found that asthma patients (women in particular) receiving long-term ICS's had significant decreases in bone mineral density, leading to decreases in body mass. If ICS's bring about weight gain, but also weight loss due to a loss of bone mineral density in women, this could further underestimate our results. Future studies need to assess not only the relationship between the prescribed doses of ICS medication, but also patient adherence to ICS's, in order to further elucidate potential causal mechanisms.

Another limitation of our study is that we were unable to acquire data on diet or physical activity levels, which was largely due to the desire to minimize patient assessment burden. However, given the observational nature of this study, it is unlikely that a significant enough change in these complex health behaviours would have likely influenced our results. We were also unable to assess hormonal status in women which has been proposed as a potential mediating factor in the BMI-asthma relationship [53]. Given that this study focused on patients treated in tertiary care, this study may not be generalizable to patients treated in primary care or community samples. However, given that our sample was comprised primarily of moderate-severe asthmatics who tend to receive the highest doses of ICS's, our focus on tertiary care asthmatics may also be viewed as appropriate and a strength, as weight gain may be relevant to this subpopulation of asthmatics due to their needs for higher doses of ICS's. Finally, as we only assessed weight change and not actual body fat, it is possible that the changes we observed reflected increases in muscle mass and not increases in adiposity. However, previous studies have shown that yearly increases in body weight in middle-aged individuals are generally driven by increases in fat mass rather than fatfree mass [54]. Future studies are needed to assess if this is also true of patients taking ICS's.

Despite some limitations, this study also has a number of important strengths. Such strengths include the use of a prospective study design as well as a well-characterized sample of moderate to severe asthmatics whose diagnoses were objectively confirmed. We assessed sex differences and included the statistical control of important covariates such as smoking cessation in our main analyses. Additionally, we used multiple imputation to deal with missing data, resulting in a complete dataset for all participants. These novel and perhaps provocative findings may stimulate future research and further inform the asthma-obesity literature.

4.2. Clinical Relevance. The consequences of obesity are serious as this condition has a profound impact on morbidity and mortality rates and is associated with other diseased states [7]. Though mechanistic studies and replications are needed, our results suggest that higher ICS doses bring about weight gain in female patients with asthma. A study conducted by Sun et al. [55] found that for every 1 unit increase of BMI, there was a $12 \%$ reduction of the odds of healthy survival. Additionally, they found that for every $1 \mathrm{~kg}$ increase in weight gain since the age of 18 , the odds of healthy survival in women decrease by $5 \%$ [55]. Given that weight gain is a concern for many patients [56], particularly women, intervening and providing help with weight control and management may encourage more patients to adhere to their medication regimen and improve asthma outcomes [57]. Applying a preventative approach to weight gain can be accomplished through referral to exercise specialists, dieticians/nutritionists, or behavioural weight management counsellors. Future studies are necessary to investigate if such an intervention can alter the potential ICS-weight gain relationship. Furthermore, given the finding that higher ICS use in men was associated with weight loss, further research is needed to explore the reasons for and potential clinical utility of this finding.

\section{Conclusion}

In a sample of 180 asthmatic patients, higher ICS doses were associated with an increase in body weight at one 
year in women and with a decreased weight in men. These findings suggest a temporal association between asthma and increased body weight among women and points to the possible role of ICS medication use. Further research is needed to clarify the extent to which this relationship is influenced by sex hormones, dietary and exercise behaviours, and medication adherence, in order to further elucidate possible mechanisms.

\section{Abbreviations}

ICS: Inhaled corticosteroids

BMI: Body mass index

CI: Confidence interval.

\section{Acknowledgments}

The authors thank Mr. Guillaume Lacoste for his invaluable assistance in patient recruitment. Funding support for this study was provided by the Social Sciences and Humanities Research Counsel of Canada (SSHRC), the Fonds de la recherche en santé du Québec (FRSQ), and the Fondation de l'Hôpital du Sacré-Cour de Montréal. Individual funding was provided by FRSQ (SLB, KLL, VP), and the Canadian Institute of Health Research (CIHR) (SLB). As well, scholarship support was provided by CIHR (AW), and the Quebec Respiratory Health Training Program (QRHTP) (AKR) sponsored by CIHR and FRSQ.

\section{References}

[1] G. C. Phua and N. R. MacIntyre, "Inhaled corticosteroids in obstructive airway disease," Respiratory Care, vol. 52, no. 7, pp. 852-858, 2007.

[2] H. Schäcke, W. D. Döcke, and K. Asadullah, "Mechanisms involved in the side effects of glucocorticoids," Pharmacology and Therapeutics, vol. 96, no. 1, pp. 23-43, 2002.

[3] D. B. Allen, L. Bielory, H. Derendorf, R. Dluhy, G. L. Colice, and S. J. Szefler, "Inhaled corticosteroids: past lessons and future issues," Journal of Allergy and Clinical Immunology, vol. 112, no. 3, supplement, pp. S1-S40, 2003.

[4] M. Ip, K. Lam, L. Yam, A. Kung, and M. Ng, "Decreased bone mineral density in premenopausal asthma patients receiving long-term inhaled steroids," Chest, vol. 105, no. 6, pp. 1722$1727,1994$.

[5] B. J. Lipworth, "Systemic adverse effects of inhaled corticosteroid therapy: a systematic review and meta-analysis," Archives of Internal Medicine, vol. 159, no. 9, pp. 941-955, 1999.

[6] "World Health Organization," Obesity and Overweight, No. 311, 2006, http://www.who.int/mediacentre/factsheets/fs311.

[7] W. Luo, H. Morrison, M. De Groh et al., "The burden of adult obesity in Canada," Chronic Diseases in Canada, vol. 27, no. 4, pp. 135-144, 2006.

[8] J. C. Celedón, L. J. Palmer, A. A. Litonjua et al., "Body mass index and asthma in adults in families of subjects with asthma in Anqing, China," American Journal of Respiratory and Critical Care Medicine, vol. 164, no. 10, part 1, pp. 1835-1840, 2001.

[9] C. C. Thomson, S. Clark, and C. A. Camargo, "Body mass index and asthma severity among adults presenting to the emergency department," Chest, vol. 124, no. 3, pp. 795-802, 2003.
[10] D. A. Beuther and E. R. Sutherland, "Overweight, obesity, and incident asthma: a meta-analysis of prospective epidemiologic studies," American Journal of Respiratory and Critical Care Medicine, vol. 175, no. 7, pp. 661-666, 2007.

[11] C. A. Camargo, S. T. Weiss, S. Zhang, W. C. Willett, and F. E. Speizer, "Prospective study of body mass index, weight change, and risk of adult- onset asthma in women," Archives of Internal Medicine, vol. 159, no. 21, pp. 2582-2588, 1999.

[12] Y. Chen, D. Rennie, Y. Cormier, and J. Dosman, "Sex specificity of asthma associated with objectively measured body mass index and waist circumference: the Humboldt study," Chest, vol. 128, no. 4, pp. 3048-3054, 2005.

[13] G. Balzano, S. Fuschillo, G. Melillo, and S. Bonini, "Asthma and sex hormones," Allergy, vol. 56, no. 1, pp. 13-20, 2001.

[14] M. Wjst and S. Dold, "Is asthma an endocrine disease?" Pediatric Allergy and Immunology, vol. 8, no. 4, pp. 200-204, 1997.

[15] A. T. Society, "Definition and classification of chronic bronchitis, asthma, and pulmonary emphysema," American Review of Respiratory Disease, vol. 85, pp. 62-68, 1962.

[16] K. L. Lavoie, S. L. Bacon, M. Labrecque, A. Cartier, and B. Ditto, "Higher BMI is associated with worse asthma control and quality of life but not asthma severity," Respiratory Medicine, vol. 100, no. 4, pp. 648-657, 2006.

[17] R. J. Knudson, M. D. Lebowitz, C. J. Holberg, and B. Burrows, "Changes in the normal maximal expiratory flow-volume curve with growth and aging," American Review of Respiratory Disease, vol. 127, no. 6, pp. 725-734, 1983.

[18] P. L. Enright, R. A. Kronmal, M. Higgins, M. Schenker, and E. F. Haponik, "Spirometry reference values for women and men 65 to 85 years of age: cardiovascular Health Study," American Review of Respiratory Disease, vol. 147, no. 1, pp. 125-133, 1993.

[19] D. B. Rubin, Multiple Imputation for Nonresponse in Surveys, John Wiley \& Sons, New York, NY, USA, 1987.

[20] F. Harrell, Regression Modeling Strategies, Springer, New York, NY, USA, 2001.

[21] Global Initiative for Asthma. Global Strategy for Asthma Management and Prevention, 2011 Update: pp. 1-110.

[22] M. Jani, S. Ogston, and S. Mukhopadhyay, "Annual increase in body mass index in children with asthma on higher doses of inhaled steroids," Journal of Pediatrics, vol. 147, no. 4, pp. 549-551, 2005.

[23] A. Hedberg and S. Rössner, "Body weight characteristics of subjects on asthma medication," International Journal of Obesity, vol. 24, no. 9, pp. 1217-1225, 2000.

[24] W. S. Beckett, D. R. Jacobs, Y. U. Xinhua, C. Iribarren, and O. Dale Williams, "Asthma is associated with weight gain in females but not males, independent of physical activity," American Journal of Respiratory and Critical Care Medicine, vol. 164, no. 11, pp. 2045-2050, 2001.

[25] Y. Chen, R. Dales, M. Tang, and D. Krewski, "Obesity may increase the incidence of asthma in women but not in men: longitudinal observations from the Canadian National Population Health Surveys," American Journal of Epidemiology, vol. 155, no. 3, pp. 191-197, 2002.

[26] I. Romieu, V. Avenel, B. Leynaert, F. Kauffmann, and F. ClavelChapelon, "Body mass index, change in body silhouette, and risk of asthma in the E3N cohort study," American Journal of Epidemiology, vol. 158, no. 2, pp. 165-174, 2003.

[27] L. P. Boulet, Q. Hamid, S. L. Bacon et al., "Symposium on obesity and asthma-November 2, 2006," Canadian Respiratory Journal, vol. 14, no. 4, pp. 201-208, 2007. 
[28] T. S. Hallstrand, M. E. Fischer, M. M. Wurfel, N. Afari, D. Buchwald, and J. Goldberg, "Genetic pleiotropy between asthma and obesity in a community-based sample of twins," Journal of Allergy and Clinical Immunology, vol. 116, no. 6, pp. 1235-1241, 2005.

[29] L. S. Inselman, L. B. Padilla-Burgos, S. Teichberg, and H. Spencer, "Alveolar enlargement in obesity-induced hyperplastic lung growth," Journal of Applied Physiology, vol. 65, no. 5, pp. 2291-2296, 1988.

[30] R. E. Kanner, J. E. Connett, M. D. Altose et al., "Gender difference in airway hyperresponsiveness in smokers with mild COPD: the lung health study," American Journal of Respiratory and Critical Care Medicine, vol. 150, no. 4, pp. 956-961, 1994.

[31] J. F. Dorgan, M. E. Reichman, J. T. Judd et al., "The relation of body size to plasma levels of estrogens and androgens in premenopausal women (Maryland, United States)," Cancer Causes and Control, vol. 6, no. 1, pp. 3-8, 1995.

[32] N. Potischman, C. A. Swanson, P. Siiteri, and R. N. Hoover, "Reversal of relation between body mass and endogenous estrogen concentrations with menopausal status," Journal of the National Cancer Institute, vol. 88, no. 11, pp. 756-758, 1996.

[33] R. Schellenberg, J. D. R. Adachi, D. Bowie et al., "Oral corticosteroids in asthma: a review of benefits and risks," Canadian Respiratory Journal, vol. 14, supplement C, pp. 1C7C, 2007.

[34] H. Derendorf, "Therapeutic review: pharmacokinetic and pharmacodynamic properties of inhaled ciclesonide," Journal of Clinical Pharmacology, vol. 47, no. 6, pp. 782-789, 2007.

[35] P. O. Sobande and C. M. Kercsmar, "Inhaled corticosteroids in asthma management," Respiratory Care, vol. 53, no. 5, pp. 625-634, 2008.

[36] D. S. Postma, "Gender differences in asthma development and progression," Gender Medicine, vol. 4, supplement 2, pp. S133S146, 2007.

[37] B. N. Melgert, A. Ray, M. N. Hylkema, W. Timens, and D. S. Postma, "Are there reasons why adult asthma is more common in females?" Current Allergy and Asthma Reports, vol. 7, no. 2, pp. 143-150, 2007.

[38] M. H. H. Chandler, S. Schuldheisz, B. A. Phillips, and K. N. Muse, "Premenstrual asthma: the effect of estrogen on symptoms, pulmonary function, and $\beta 2$-receptors," Pharmacotherapy, vol. 17, no. 2, pp. 224-234, 1997.

[39] S. P. Hanley, "Asthma variation with menstruation," British Journal of Diseases of the Chest, vol. 75, no. 3, pp. 306-308, 1981.

[40] B. D. Pauli, R. L. Reid, P. W. Munt, R. D. Wigle, and L. Forkert, "Influence of the menstrual cycle on airway function in asthmatic and normal subjects," American Review of Respiratory Disease, vol. 140, no. 2, pp. 358-362, 1989.

[41] R. J. Troisi, F. E. Speizer, W. C. Willett, D. Trichopoulos, and B. Rosner, "Menopause, postmenopausal estrogen preparations, and the risk of adult- onset asthma: a prospective cohort study," American Journal of Respiratory and Critical Care Medicine, vol. 152, no. 4, part 1, pp. 1183-1188, 1995.

[42] C. S. Mantzoros, "The role of leptin and hypothalamic neuropeptides in energy homeostasis: update on leptin in obesity," Growth Hormone and IGF Research, vol. 11, supplement A, pp. S85-S89, 2001.

[43] T. Tsuchiya, H. Shimizu, T. Horie, and M. Mori, "Expression of leptin receptor in lung: leptin as a growth factor," European Journal of Pharmacology, vol. 365, no. 2-3, pp. 273-279, 1999.
[44] M. F. Saad, S. Damani, R. L. Gingerich et al., "Sexual dimorphism in plasma leptin concentration," Journal of Clinical Endocrinology and Metabolism, vol. 82, no. 2, pp. 579-584, 1997.

[45] J. M. Bruun, S. B. Pedersen, K. Kristensen, and B. Richelsen, "Effects of pro-inflammatory cytokines and chemokines on leptin production in human adipose tissue in vitro," Molecular and Cellular Endocrinology, vol. 190, no. 1-2, pp. 91-99, 2002.

[46] M. M. Meguid, S. O. Fetissov, M. Varma et al., "Hypothalamic dopamine and serotonin in the regulation of food intake," Nutrition, vol. 16, no. 10, pp. 843-857, 2000.

[47] L. P. Boulet, "Influence of obesity on the prevalence and clinical features of asthma," Clinical and Investigative Medicine, vol. 31, no. 6, pp. E386-E390, 2008.

[48] R. Sundberg, K. Torén, K. A. Franklin et al., "Asthma in men and women: treatment adherence, anxiety, and quality of sleep," Respiratory Medicine, vol. 104, no. 3, pp. 337-344, 2010.

[49] M. F. Kuczmarski, R. J. Kuczmarski, and M. Najjar, "Effects of age on validity of self-reported height, weight, and body mass index: findings from the third National Health and Nutrition Examination Survey, 1988-1994," Journal of the American Dietetic Association, vol. 101, no. 1, pp. 28-36, 2001.

[50] L. K. Williams, M. Pladevall, H. Xi et al., "Relationship between adherence to inhaled corticosteroids and poor outcomes among adults with asthma," Journal of Allergy and Clinical Immunology, vol. 114, no. 6, pp. 1288-1293, 2004.

[51] M. G. Cochrane, M. V. Bala, K. E. Downs, J. Mauskopf, and R. H. Ben-Joseph, "Inhaled corticosteroids for asthma therapy: patient compliance, devices, and inhalation technique," Chest, vol. 117, no. 2, pp. 542-550, 2000.

[52] A. Roy, K. Battle, L. Lurslurchachai, E. A. Halm, and J. P. Wisnivesky, "Inhaler device, administration technique, and adherence to inhaled corticosteroids in patients with asthma," Primary Care Respiratory Journal, vol. 20, no. 2, pp. 148-154, 2011.

[53] R. Varraso, V. Siroux, J. Maccario, I. Pin, and F. Kauffmann, "Asthma severity is associated with body mass index and early menarche in women," American Journal of Respiratory and Critical Care Medicine, vol. 171, no. 4, pp. 334-339, 2005.

[54] W. E. Kraus, J. A. Houmard, B. D. Duscha et al., "Effects of the amount and intensity of exercise on plasma lipoproteins," The New England Journal of Medicine, vol. 347, no. 19, pp. 14831492, 2002.

[55] Q. Sun, M. K. Townsend, O. I. Okereke, O. H. Franco, F. B. Hu, and F. Grodstein, "Adiposity and weight change in mid-life in relation to healthy survival after age 70 in women: prospective cohort study," BMJ, vol. 339, article b3796, 2009.

[56] L. P. Boulet, "Perception of the role and potential side effects of inhaled corticosteroids among asthmatic patients," Chest, vol. 113, no. 3, pp. 587-592, 1998.

[57] H. Pijl and A. E. Meinders, "Bodyweight change as an adverse effect of drug treatment. Mechanisms and management," Drug Safety, vol. 14, no. 5, pp. 329-342, 1996. 


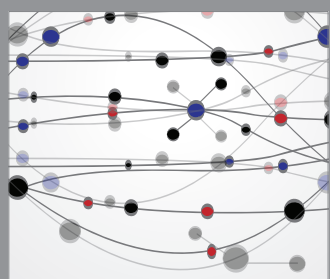

The Scientific World Journal
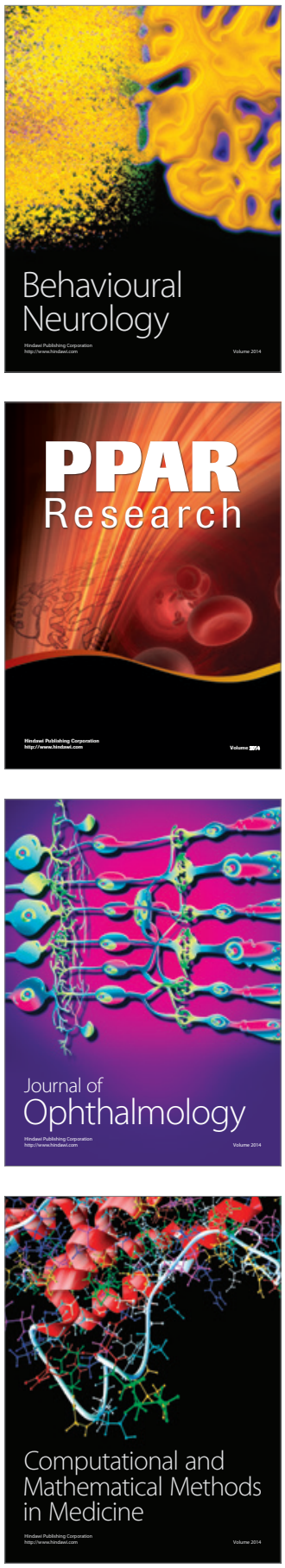

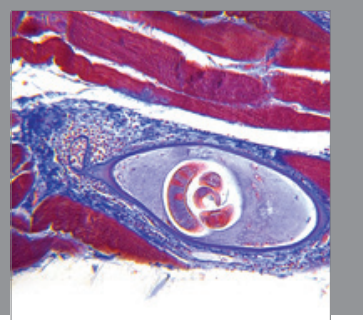

Gastroenterology

Research and Practice
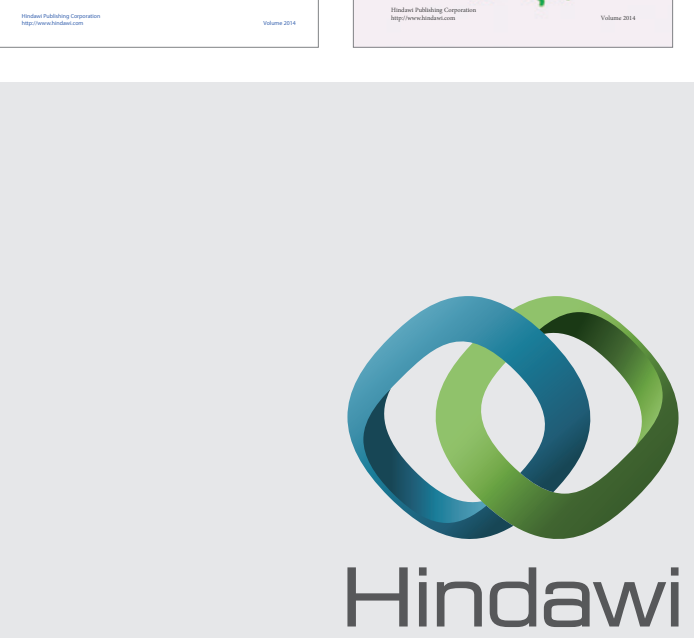

Submit your manuscripts at

http://www.hindawi.com
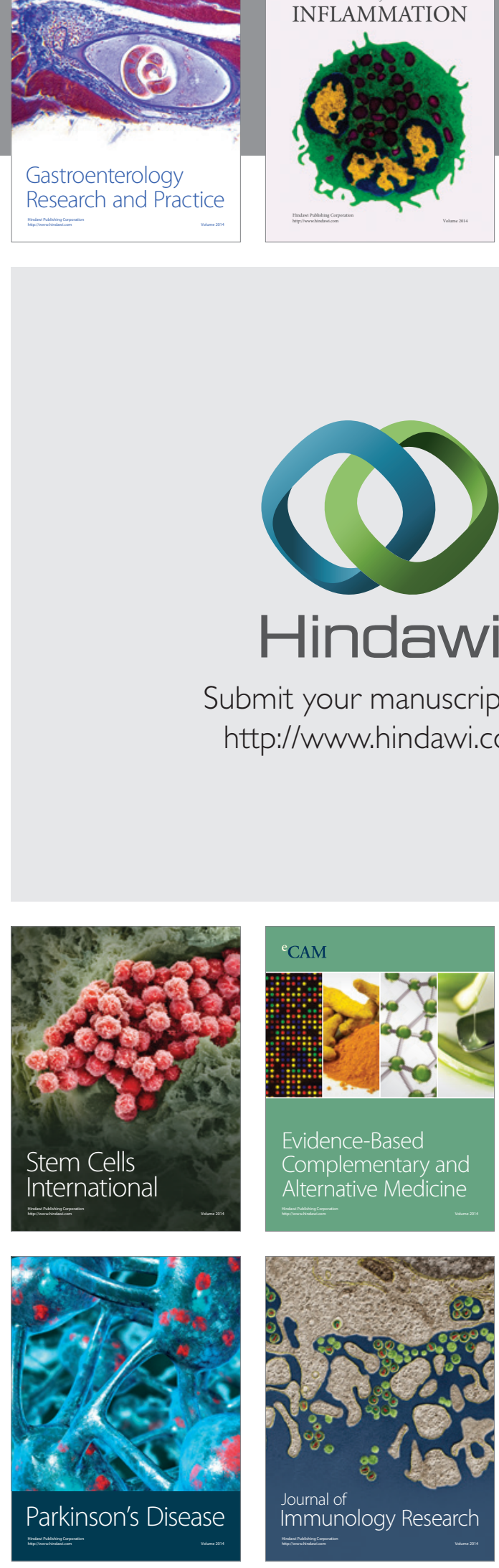

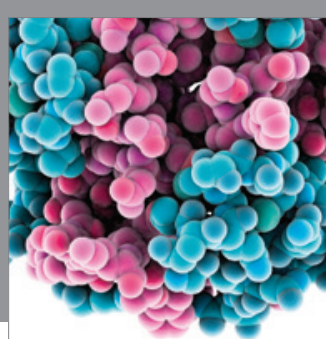

Diabetes Research
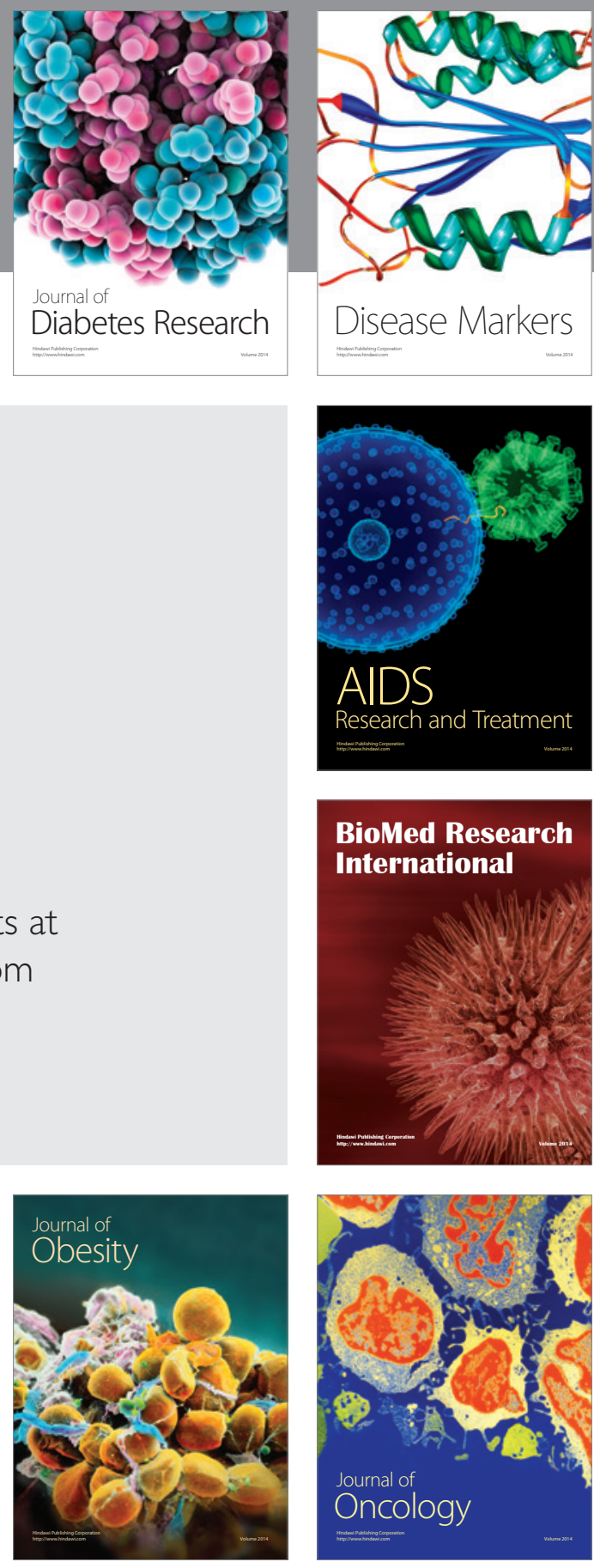

Disease Markers

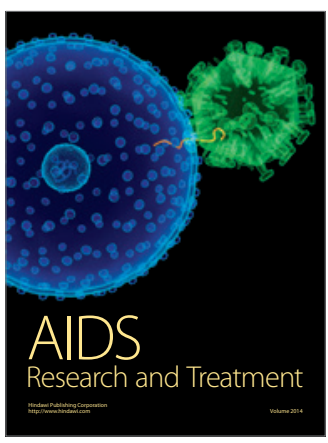

BioMed Research

International
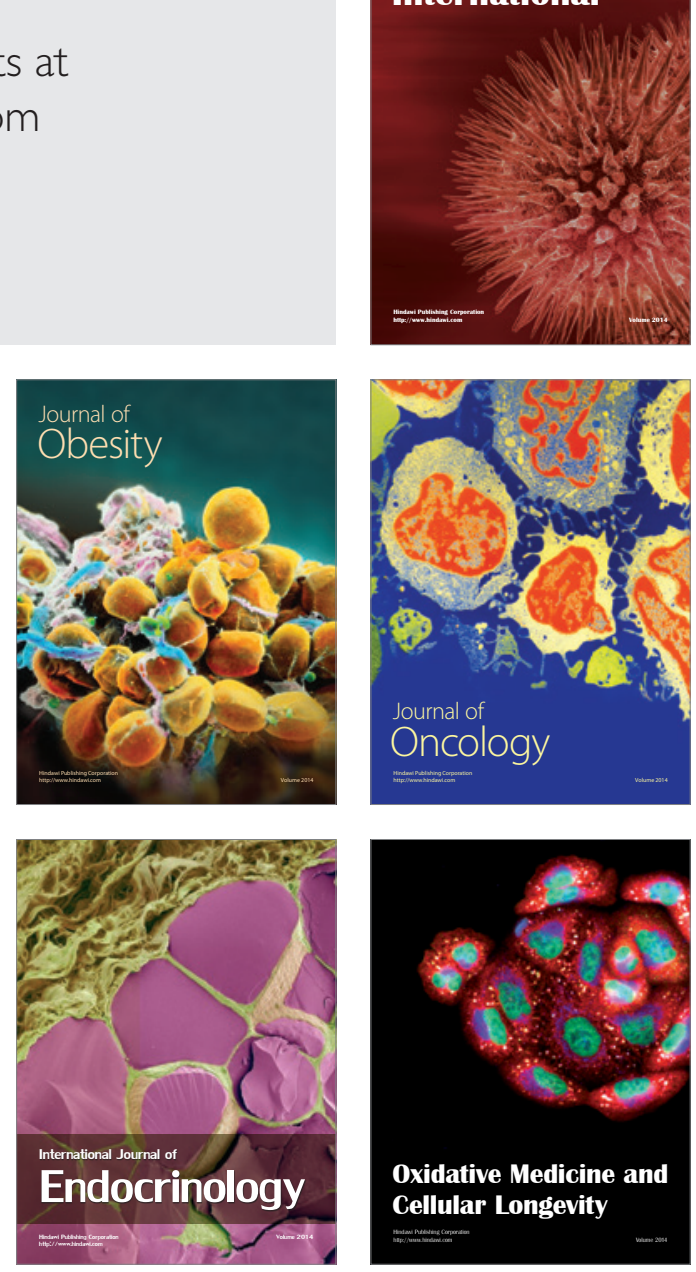